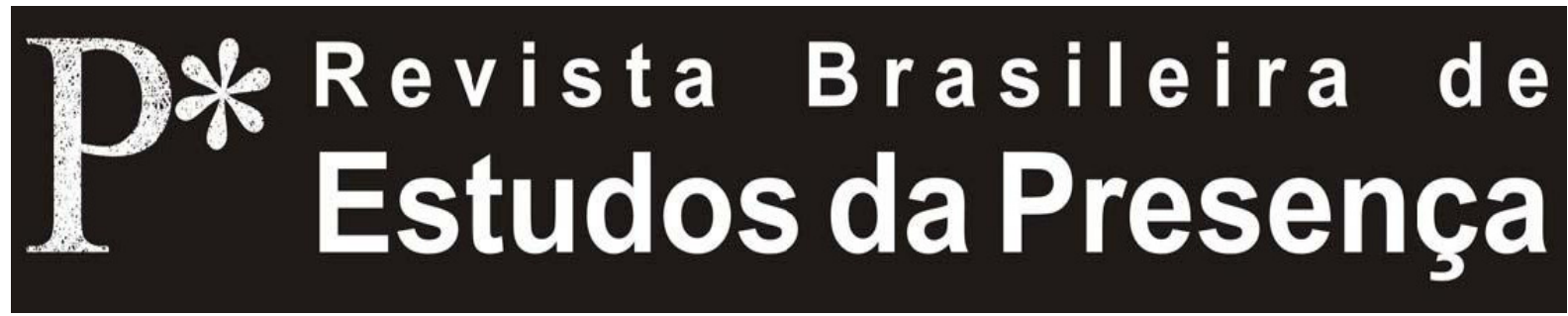

DOI - http://dx.doi.org/10.1590/2237-266039426

ISSN 2237-2660

\title{
La Corporalidad Travesti en la Deformance Poética de Naty Menstrual
}

\author{
Guillermina Bevacqua \\ Universidad de Buenos Aires - UBA, Buenos Aires, Argentina
}

RESUMEN - La Corporalidad Travesti en la Deformance Poética de Naty Menstrual $^{1}$ - En el año 2007, el Área de Tecnologías de Género y el Área de Comunicación del Centro Cultural Rojas (UBA) publicó El Teje. La primera revista de travestis en América Latina. Desde ella, la institución promovió la inclusión de personas trans y cuestionó la binaridad genérica propia del pensamiento heterosexual. Varias de las presentaciones de lanzamiento de la revista fueron acompañadas por performances escénicas. Aquí, abordamos la construcción de la identidad travesti corporalizada por la poeta y performer Naty Menstrual en la primera presentación de El Teje. Para tal fin, utilizamos aportes de la teoría del campo teatral posdramático aplicados al campo de los estudios queer.

Palabras-clave: Teatro Posdramático. Deformances. Identidad. Corporalidad. Travestis.

ABSTRACT - Transvestite Corporeality in the Poetic Deformance of Naty Menstrual - In 2007, the Area of Gender's Technology and the Area of Communication of Centro Cultural Rojas (UBA) published El Teje. The first magazine of transvestites in Latin America. From it, the institution promoted the inclusion of transgender persons and questioned the dualism typical of the heterosexual contract. Many presentations of the magazine were accompanied by performances. We have studied the construction of the transvestite identity embodied by poet and performer Naty Menstrual in the first presentation of El Teje. For this, we apply postdramatic theatrical theory to the field of queer studies.

Keywords: Postdramatic Theatre. Deformances. Identity. Embodiment. Transvestites.

RÉSUMÉ - La Corporéité Travestie dans les Déformances Poétiques de Naty Menstrual - En 2007, les départements des Technologies de Genre et de Communication du Centre Culturel Rojas (UBA) ont publié El Teje. La première revue travesti de l'Amérique Latine. Depuis, l'institution a promu l'inclusion de personnes transéxuelles, questionant la bipolarité générique propre à la pensée hétérosexuelle. Nombreuses cérémonies de lancement de la revue ont été accompagnéés de performances scéniques. Cet article propose donc une réflexion sur la construction de l'identité travesti du poète et performer Naty Menstrual dans la première présentation de El Teje. Cette analyse s'appuiera sur la théorie théâtrale postdramatique appliquée au champ des études queer.

Mots-clés: Théâtre Postdramatique. Déformances. Identité. Corporalité. Travesti. 


\section{Introducción}

En el año 1984, la Universidad de Buenos Aires fundó el Centro Cultural Rector Ricardo Rojas (CCRR). Desde sus inicios, la institución se caracterizó por ser un semillero de propuestas culturales innovadoras. A partir de ellas, tanto sus producciones artísticas como sus cursos y programas lograron forjar un estrecho vínculo con la sociedad. Desde el año 2007, el Área de Tecnologías de género, en conjunto con el Área de Comunicación, publican El Teje. La primera revista de travestis en América Latina. A partir de dichas Âreas, la institución promovió el reconocimiento a la libre identidad de género. En consecuencia, el Rojas fue una de las primeras instituciones públicas que aceptó, incluyó, desnaturalizó y cuestionó la binaria heteronormatividad de género.

Tras ańos de maltrato y discriminación, una gran cantidad de personas trans comenzaron a ser reconocidas por el Estado a partir de la Ley de Identidad de Género ${ }^{2}$. Esta ley fue producto de un largo recorrido de luchas por parte de diferentes agrupaciones LGTBIQ (lesbianas, gays, travestis, transexuales, transgéneros, bisexuales, intersex, queer). En muchos casos, dichas luchas adquirieron visibilidad a partir de propuestas artísticas generadas por agrupaciones artivistas $^{3}$. Este fue el caso de la organización Futuro Transgenérico cuya coordinadora, Marlene Wayar, también es la directora de $E l$ Teje. Tanto desde la organización mencionada, como desde la revista publicada por el CCRR, Marlene Wayar abogó por una construcción de la corporalidad tal obra de arte, en su opinión, única e irrepetible. Asimismo, incluyó en las presentaciones de El Teje propuestas escénicas en las que los cuerpos subvirtieron y multiplicaron la variabilidad genérica.

Las performances teatrales acompañaron varios de los lanzamientos de El Teje en el Centro Cultural Rojas ${ }^{4}$. La primera presentación del periódico fue uno de los eventos de mayor envergadura en el que el Centro Cultural Rojas reconoció la libre identidad de las personas trans en general y las identidades travestis en particular. Aquella ocasión fue acompañada por las performance de Julia Lagos y Dominique Sanders, Julia Amore, Naty Menstrual y Fernando Noy. Consideramos que cada una de ellas presentaron diferentes identidades trans no regidas por una estética teatral unificada. No obstante, si las aunó una propuesta ideológica común, ésta consistió en desestabilizar las estancas y binarias categorías de género y fes- 
tejar sus corporalidades, a pesar de restricciones constitutivas de las matrices heteronormativas.

Por lo expuesto, consideramos importante emprender una reflexión sobre la relación de la construcción de la identidad travesti y el hecho teatral en el Centro Cultural Rojas. Para ello, abordaremos la performance (deformance) poética realizada por la poeta Naty Menstrual en la primera presentación de la revista. Para tal fin, desarrollaremos nuestro estudio desde la perspectiva teórica del teatro posdramático (Lehmann, 2010; Cornago, 2005) y los estudios del campo de la performance (Taylor, 2005; Schechner, 2000). Y, desde una perspectiva semiótica (Pavis, 2005; Trastoy; Zayas de Lima, 1997; 2006), analizaremos los lenguajes escénicos desde lo que Naty Mentrual construyó su corporalidad. Para alcanzar una mayor comprensión sobre la construcción de la identidad, nos valdremos de los aportes de los estudios queer tanto del campo filosófico (Butler, 2008; 2007; 2006a; 2006b) como del campo antropológico argentino (Fernández, 2004).

Proponemos un variado marco teórico como herramientas de análisis. En este confluyen diferentes disciplinas y perspectivas. A partir de tal variedad desarticulamos miradas unívocas. En tal sentido, destacamos la pluralidad disciplinaria en diálogo tanto con la propia voz de Naty Menstrual como con la nuestra. A partir de la confluencia de nuestras voces y el campo teórico propuesto desarrollamos un territorio político-subjetivo capaz de esbozar, "[...] mostrar, describir, de qué modo los seres humanos se ocupan en hacer que determinados objetos del pensamiento se vuelvan importantes para determinados grupos sociales en determinadas épocas" (Icle, 2012, p. 193). Tal interlocución permitió una reflexión sobre otros modos de estar presente.

Si bien intentamos acercarnos a la perspectiva de los Estudios de la Presencia lo hacemos a partir de flexibilizar los márgenes propuestos tanto por la Semiótica como por los Estudios de las performances. En igual sentido, la propia voz de Naty Menstrual y sus autodefiniciones demandaron de nuestra plasticidad para desbaratar categorías y priorizarlas por sobre nuestra tradición académica. Por ello, el marco teórico anteriormente seńalado solo es el punta pie inicial propuesto para dialogar y articular el campo de la teoría con el campo de la práctica artística de Naty Menstrual. 
Desde los comienzos de nuestra investigación sobre las identidades trans en el Centro Cultural Rojas (2007) adoptamos la articulación de tales campos como metodología de trabajo. Creemos que nuestro discurso carece de valor si no cuenta con la voz de las propias hacedoras. Por tal motivo, en general, desde los primeros tiempos de lanzamiento de El Teje mantenemos con Marlene Wayar un continuo diálogo que orientó las reflexiones planteadas en nuestro proyecto de investigación doctoral denominado Construcción de Identidades trans en las propuestas teatrales del Centro Cultural Rojas: Desde Batato Barea a El Teje. Y, en particular, el presente trabajo se basa en los diálogos que mantuvimos con Naty Menstrual para la elaboración del mismo. Tanto Wayar como Menstrual sintetizan los discursos más radicales surgidos al calor de los debates por la Ley de Identidad de género 5 . Consideramos que la interlocución desarrollada con Wayar y Menstrual le otorgaron a nuestra labor la oportunidad de ir un poco "más allá de la interpretación" (Icle, 2012, p. 202).

\section{El Devenir Travesti de Naty Menstrual}

En la primera presentación de El Teje, la corporalidad travesti de Naty Menstrual fue el punto de partida tanto de la acción como de la narración poética. El presente estudio concibe la identidad como un devenir, en este caso, un devenir travesti. Dicho devenir corresponde a modos alternativos y disidentes de subjetivación que abren puntos de fugas en la sociedad capitalista (Palmeiro, 2010, p. 23). "Devenir no es transformarse en otro, sino entrar en alianza (aberrante), en contagio, en inmistión con el (lo) diferente. El devenir no ya de un punto al otro, sino que entra en el 'entre' del medio, es ese 'entre'. Devenir animal no es volverse animal, sino tener los funcionamientos del animal" (Perlongher, 1997, p. 68). Desde esta perspectiva identitaria, para muchas personas trans de la conducción y del equipo de redacción de El Teje, ser trans no es ser ni hombre ni mujer. Anclarse en dichas categorías implicaría reforzar la binaridad genérica y anular la identidad travesti. Así lo explicó Marlene Wayar (2012, s/p) al referirse a la promulgada Ley de Identidad de género:

¿Qué nos solicita esta ley? Que dejemos de ser eso que somos y que debería ser reconocido como nuestra identidad. Si lo pasamos a otras identidades colectivas sería como si a las personas afrodescendientes se les pidiera que maquillen su negritud para evitar el racismo o si personas judías 
tuvieran que parecer cristianas y vivir de modo oculto su religión para no ser víctimas del antisemitismo (Wayar, $2012, s / p)$.

La identidad no es una categoría uniforme ni estable a través del tiempo. En consecuencia, es una categoría que nunca podrá describir plenamente a aquellos a quienes pretende representar. Sin embargo, como señaló Judith Butler (2006), la generalización y estabilidad temporal de la identidad es un error necesario. A partir de ella, existen categorías de reconocimiento necesarias para la variedad de los cuerpos. En conclusión, la categoría forma "[...] parte de un mapa dinámico de poder en cual se constituyen y/o suprimen, se despliegan y/o se paralizan las identidades" (Butler, 2008, p. 176).

Consideramos que la performance poética de Naty Menstrual materializó el devenir de la corporalidad travesti. La poeta puso en escena el carácter ficcional y contingente de la identidad. Al mismo tiempo, su performance sedimentó los procesos de estabilización a partir de los cuales se instituyen las categorías de reconocimiento.

La presentación de Naty Menstrual consistió en la lectura de tres poemas ${ }^{6}$. Lejos de considerar la preeminencia de lo verbal sobre lo corporal, nuestro estudio comprende la igualdad de los lenguajes escénicos verbales y no verbales. En consecuencia, entendemos que, si bien en la presentación de Naty Menstrual predominó el rol de la palabra, no podemos soslayar los lenguajes escénicos que construyeron su identidad y corporalidad travesti. Dicha corporalidad resultó altamente significativa, al punto que podemos considerarla como metáfora estructurante y complementaria de su poética. En ella, los diferentes lenguajes escénicos produjeron una tensión sígnica propia de la estética propuesta por la escritora. Por un lado, su vestuario y maquillaje se correspondieron con una mimesis de modelos femeninos. Por otro lado, su voz y gestualidad se distanciaron de tal mimesis. En este sentido, el travestismo cuestionador (Trastoy; Zayas de Lima, 2006) de Naty Menstrual apeló a estereotipos de modelos femeninos, a la vez que los deconstruyó. De esta manera, la poeta desestabilizó las categorías binarias de género. Dicha desestabilización no se sujetó solamente a su corporalidad, sino también a la concepción y definición de su trabajo. A continuación, consideraremos su poética desde conceptualizaciones del campo de la teoría teatral. 


\section{Teatro Posdramático y el Devenir de la Performance en Deformances}

Lehmann (2010) acunó la definición de teatro posdramático para englobar a aquellas prácticas teatrales, surgidas en la década de 1970, que se distanciaron de las formas tradicionales de representación teatral. En modo general, estas prácticas se caracterizaron por relativizar la importancia del texto dramático. En tal sentido, el texto se enmarcó en la horizontalidad de los demás significantes escénicos. El investigador alemán también destacó la tendencia a la autorreflexión y autotematización de estas prácticas teatrales. Asimismo señaló que el teatro posdramático invita a preguntarnos "[...] qué nuevas posibilidades de pensamiento y de representación son delineadas aquí para el sujeto humano" (Lehmann, 2010, p. 4). Ampliamos la incógnita de Lehmann a las performances de la primera presentación en general, $y$, en particular, a la presentación de Naty Menstrual y nos preguntamos: ¿qué nuevas posibilidades de pensamiento y representación instauran las travestis en la escena teatral porteña?

La presentación de Naty Menstrual consistió en la lectura en acto de sus escritos tal rapsoda posmoderno. La poeta empleó técnicas de interpelación al público propias del stand up. Tras derribar la cuarta pared, Naty Menstrual estableció una complicidad picaresca con sus especta-lectores.

La poeta desarrolló una intensa teatralidad de ella misma y el devenir travesti. En ésta, se alzó como protagonista de su propia puesta. Ella misma se erigió como sujeto y objeto al mismo tiempo. En consecuencia, el límite entre lo ficcional y real se desdibujó. Y generó una dualidad borrosa que desvaneció los límites tradicionales del personaje teatral. Por lo tanto, las categorías entre persona y personaje se fusionaron para tomar cuerpo en la categoría de performer. En tanto que el performer es aquel que habla y actúa en nombre suyo (Pavis, 2005, p. 334), Naty Menstrual hizo una puesta en escena de su propio yo. Es decir, actúo y narró en su nombre y no en representación de otro (personaje). Los relatos de ella misma fueron la materia prima sobre la que construyó su propia poética. A partir de ellos, su presentación se acercó al teatro autobiográfico. Según Naty Menstrual, la narración sobre su propio yo es algo intrínseco a todo escritor:

Ningún escritor puede escribir algo que no sea un poco autobiográfico, porque lo que surge es en función de la vida que vas viviendo. El hombre no puede escribir sobre algo que no conoce, por más que sea un maestro de la ciencia 
ficción. Tuve un profesor de guión que valoré mucho. Decía: 'El hombre tiene situaciones que lo marcaron a fuego en su vida y de ahí no puede salir. Puede reversionar, ponerle otra pincelada, no mucho más' (apud Dema, 2011, s/p).

En la presentación de Naty Menstrual su presencia adquirió una categoría estética. Ella misma corporizó su literatura travesti trash (como ella misma se definió). En tal acto, la narración de sus relatos y poemas constituyeron una extensión de su escritura.

Como señalamos, los diversos lenguajes escénicos operaron a partir de juegos de oposición y contraste. En este sentido, el maquillaje y el vestuario conformaron una imagen hiperbólicamente femenina. No obstante, fue desbaratada por la masculinidad translucida tanto en su gestualidad como en su voz. A partir de esta construcción de personaje inorgánica, la poeta desestabilizó la representación de género convencional y tematizó así la construcción de la identidad.

Según Óscar Cornago (2005), la disonancia escénica es propia de la teatralidad posdramática. Tal disonancia entró en juego con el carácter procesual de la construcción de la identidad trans de Naty Menstrual. Y, lejos de reducir una categoría genérica a otra o promulgar un tercer género 7 , Naty Menstrual hizo estallar las posibilidades de categorización de su identidad. De esta manera, su corporalidad produjo un derrumbamiento de fronteras y se resistió (políticamente) a una identidad travesti tradicional ${ }^{8}$. Ineludiblemente, su presentación rearticuló y sedimentó el proceso temporal de la construcción de la identidad travesti.

Según Schechner (2000, p. 13), las performances “[...] marcan identidades, tuercen y rehacen el tiempo, adornan y remodelan el cuerpo, cuentan historias, permiten que la gente juegue con conductas repetidas, que se entrene y ensaye, presente y re-presente esas conductas". A partir de la repetición de la actuación del género, Naty Menstrual produjo fallas y fisuras en el devenir de las identidades trans?.

En la misma línea, Diana Taylor (2005) señaló que las performances funcionan como actos vitales de transferencia de saber social, una realización y un medio de intervenir en el mundo que implica memoria e identidad, al tiempo que constituye una perspectiva epistemológica. Por la apertura semántica del término ${ }^{10}$, Taylor concluyó que la noción de performances instaura un desafío no sólo para los hablantes de español o portugués quienes no contamos con la traducibilidad del término, sino también, para los angloparlantes, 
quienes creían que comprendían lo que significaba performances. Tal dificultad presentó el trabajó de Naty Menstrual. Ella misma cuestionó el significado de performance y negó categorizar su presentación bajo tal nominación ${ }^{11}$. Continuando con su propuesta de desbaratar las convenciones, consideró que sus lecturas de poemas, a lo sumo, se podrían denominar como deformances. El neologismo utilizado por la artista describe el sentido de su deconstrucción-travesti-trash. Naty Menstrual deformó lo establecido y esperado socialmente de las definiciones y representaciones de género.

Ante la indefinición del término performances y la des-identificación propuesta por Naty Menstrual, destacamos la interpretación pragmática realizada por Schechner. Según el investigador teatral, algo "es una performance cuando una cultura particular, la convención y la tradición dicen que lo es" (Schechner, 2000, p. 13). Más allá de las definiciones, Schechner destacó la importancia de abordar los estudios como performance. Es decir, estudiar cómo las practicas teatrales repiten a la vez que modifican el carácter performativo de representaciones identitarias. Tras abordar los lenguajes escénicos, profundizaremos el análisis de la deconstrucción de género que Naty Menstrual realizó en su deformance.

\section{Materialidad de los Lenguajes Escénicos}

Butler reflexionó sobre la identidad y se preguntó cómo se construye la materialidad de los cuerpos. En Cuerpos que importan (2008) indicó que no basta con sostener que el sujeto es una construcción. Por ello propuso retornar a la noción de materia, "[...] como un proceso de materialización que se estabiliza a través del tiempo para producir el efecto de frontera, de permanencía y de superficie que llamamos materia" (2008, p. 28 - la cursiva en el original).

Luego de ratificar que los géneros no son ni verdaderos ni falsos, sino que sólo se crean como los efectos de verdad de un discurso punitivo de identidad primaria y estable, Butler sentenció que el género es una fantasía instaurada y circunscripta a la superficie de los cuerpos. Para la filosofa:

La actuación de la travestida altera la distinción entre [...] tres dimensiones contingentes de corporalidad significativa: el sexo anatómico, la identidad de género y la actuación de género [...] La travestida muestra el carácter diferente de los elementos de la experiencia de género que erróneamente 
se han naturalizado como una unidad mediante la ficción reguladora de la coherencia heterosexual. Al imitar al género, la travestida manifiesta de forma implícita la estructura imitativa del género en sí, así como su contingencia (Butler, 2007, p. 268-269 - la cursiva es del texto).

Tradicionalmente, la materialización de la corporalidad travesti se realizó a partir de una mimesis del cuerpo femenino. Los modelos femeninos que han servido como horizonte son los de las mujeres en situación de prostitución y las vedettes de los espectáculos de revista. Estos cuerpos están altamente narrativizados por el lenguaje de la moda y la belleza (Fernández, 2004) ${ }^{12}$.

Consideramos que los lenguajes escénicos ${ }^{13}$ constituyen la materia prima desde la que Naty Menstrual desnaturalizó el género y materializó su corporalidad travesti. Por ello, abordaremos la interrelación establecida entre el vestuario y maquillaje, la voz, la gestualidad y la palabra. Por su parte, el vestuario y el maquillaje, como tantas otras matrices de género, están sujetos a normas culturales que conforman una anátomo-politica de la belleza (Citro, 2010) de la imagen corporal de la mujer y, por extensión, de las travestis. Ésta nos permite dilucidar esquemas históricos y gestus sociales que toda obra testimonia. Por tal motivo, creemos oportuno reflexionar sobre la materialización de la identidad travesti a partir del vestuario y el maquillaje.

Naty Menstrual intervino su vestuario y lo reformó de acuerdo a su travestismo trash como gesto de provocación al sistema de la moda ${ }^{14}$. Su vestuario de feria americana ${ }^{15}$ no está sujeto a una moda actual, pero si puede estar sujeto a modas anteriores. El atuendo elegido para la presentación del primer lanzamiento de El Teje fue un vestido negro con brillo acompañado de una boa de plumas negras y un sombrero estilo cloche. Este vestuario respondió a convenciones genéricas propias de las divas del mundo de los espectáculos cinematográficos. Por lo tanto, Naty Menstrual puso de manifiesto uno de los esquemas históricos (Barthes, 1967) sobre el que las travestis han construido su imagen corporal. En relación a su vestuario, Marlene Wayar señaló:

Naty Menstrual, se vino con su glamour de cine condicionado, con imagen de diva de los veinte a lo Gloria Swanson y la sexualidad mórbida a flor de piel, igual a las busconas del conurbano bonaerense (una suerte de travestismo trash) (Wayar, 2008, p. 2). 
A partir del estudio de Josefina Fernández (2004) señalamos que las travestis construyeron su imagen corporal a través de modelos femeninos narrativizados. Wayar consideró que estos modelos fueron tanto el de las divas cinematográficas como el de las busconas ${ }^{16}$ bonaerenses. Y homologó la figura de Naty Menstrual a la figura de Gloria Swanson. Dicha actriz fue uno de los íconos más glamorosos del cine mudo. En la época de su esplendor fue joven, bella, exitosa y millonaria y, por ello, simbolizó la libertad femenina. En los años 1920, la imagen de Gloria Swanson fue uno de los paradigmas del estilo andrógino o moda a la garçonne ${ }^{17}$.

La imagen corporal construida por las travestis en general, y por Naty Menstrual en particular, también se realizó a partir de las funciones sociales básicas del maquillaje. La anátomo política de la belleza de la mujer implementó un uso disciplinado de este como estrategia para su pleno funcionamiento ${ }^{18}$.

En nuestra sociedad heteronormativa, el uso del maquillaje social opera como matriz simbólica de adultez y femineidad. Las adolescentes comienzan a maquillarse como signo de crecimiento e independencia en la construcción de su propia imagen. Luego, el mismo maquillaje sirve para ocultar imperfecciones de la piel propias del paso del tiempo. Tanto en la adolescencia como en la adultez, el uso del maquillaje social estiliza el rostro y sirve para destacarlo y embellecerlo. Como atractivo o como disimulador el maquillaje restaura (e instaura) una imagen de belleza normativa.

El maquillaje teatral cumple las funciones de estilizar o transformar el rostro. A su vez, potencia la construcción del personaje o performer. Tal máscara superpuesta amplia las posibilidades de resonancia del performer y se adecua a la psicología del personaje. Beatriz Trastoy y Perla Zayas de Lima (2006) seńalaron que el maquillaje roza la frontera de lo transgresivo, ya que, con su poder de metamorfosis puede invertir el orden de lo establecido. En este sentido, consideramos que el maquillaje es consustancial al travestismo. Y, aunque en su mínima utilización, es imprescindible para la caracterización de una travesti ${ }^{19}$.

En la presentación del primer lanzamiento de El Teje, Naty Menstrual utilizó un económico maquillaje. Este denotó un rostro que intentó ser natural. En primera instancia, una espesa base de maquillaje desvaneció las marcas de la piel y la rectitud de sus rasgos faciales. En segunda instancia, sus párpados superiores fueron discre- 
tamente coloreados con tonos piel beige-tierra y con un toque de luz en el arco de su párpado superior. Para resaltar sus ojos, delineó con un negro intenso tanto su parpado inferior como su parpado superior. A partir de dicho delineado logró profundizar su mirada. Por último, pintó con un rojo mate sus labios. Tal maquillaje fue consustancial al vestuario. Ambos, sin ser una copia mimética ni reconstrucción histórica de la moda de los años 1920, denotaron rasgos de época.

Por lo expuesto, consideramos que el vestuario de Naty Menstrual recuperó aquella imagen femenina que en la década de 1920 cuestionó el tradicional rol de la mujer en la sociedad. En esta oportunidad, la performer refuncionalizó dicha moda e imagen para cuestionar las identidades genéricas actuales. Por consiguiente, el vestuario y el maquillaje operaron tal gestus social, es decir, fueron la expresión exterior y material de los conflictos de la sociedad de los que toda obra brinda testimonio (Barthes, 1967, p. 65). Ambos lenguajes escénicos sedimentaron la identificación de modelos femeninos a partir de los que las travestis materializaron su identidad. Al mismo tiempo, la anátomo politica del vestuario y maquillaje de Naty Menstrual develó el carácter performativo del género y no natural ni esencialista, sino contingente de las identidades (Butler, 2008, p. 1749). Según Pavis (2005, p. 507), el vestuario no es solo el ornamento y embalaje exterior, sino que también sirve a la gestualidad, actitud y desplazamiento del actor. Por ello, consideraremos la interrelación que establecieron el maquillaje y el vestuario tanto con la gestualidad como con la voz y la escritura de Naty Menstrual.

Pavis (2005) diferencia la gestualidad del gesto. Según el investigador, el gesto refiere a una acción corporal singular. Mientras que la gestualidad constituye un sistema más o menos coherente de maneras de ser corporales. En tal sentido, la gestualidad de Naty Menstrual no fue autónoma en relación a los demás lenguajes escénicos. Sus gestos estilizaron su figura de modo realista. Sin embargo, la caracterización de los modelos femeninos fue realizada en una economía gestual que se distanció de las imágenes convencionales de las travestis que imitan a las vedettes o las prostitutas despampanantes. Tal distancia fue aun más profunda en la caracterización de la voz. Aunque la performer tiene extensos conocimientos sobre la modulación de la voz ${ }^{20}$, no se sirvió de ellos para desarrollar una caracterización de un personaje orgánico. A partir de la oralidad, Naty Menstrual se distanció de la estilización femenina propuesta 
por su imagen corporal. El cuerpo de su voz no imitó matices y modulaciones propias de las voces femeninas ${ }^{21}$.

Como señalamos, a partir del vestuario y el maquillaje y de la gestualidad y la voz, Naty Menstrual construyó una corporalidad que se distanció de una copia mimética de los modelos de mujer narrativizados por la sociedad heteronormativa. Tal falla en la performatividad del género la realizó también desde sus relatos. En su escritura, la performer también desdibujó las convenciones sociales y textuales. Jorge Luis Peralta sobre el trabajo de Naty Menstrual señaló que:

Diversos géneros, literarios y sexuales, se baten textualmente [...], mezclándose, superponiéndose, desafiándose unos a otros: en la poesía afloran, a veces, trazos narrativos; en los cuentos hay momentos poéticos - pero de una poesía escatológica, brutal; las crónicas condensan elementos de una y de otros: como siempre en la literatura de la autora, los límites son difusos y, a fin de cuentas, innecesarios" (Peralta, 2012, p. 7).

En la primera presentación de El Teje, Naty Menstrual leyó "Yo quiero tetas" (2012, p. 197-202). El lenguaje travesti y guarro se puede apreciar en su transcripción literal:

Yo quiero tetas/ Dos grandes tetas/ Dos hermosas tetas/ Dos jugosas tetas/ O más/ Y por qué no/ Perra de muchas tetas/ Colección invaluable de pezones/ Amamantadora incondicional de pilas incalculables/ de casados amantes silenciosos/ que escupan lejos elixir blanco/ de travesti macho/ Dos tetas/que hagan juego con mi pija/ salvaje y recta/ Frotarme los soñados pezones/ contra las paredes ásperas/ de Buenos Aires/ Y borrar grafittis fascistas/ a un ritmo enloquecido/ como mágicamente poseída/ por un danzar/ de gomas de borrar/ de tinta y lápiz/ Refrescar mis tetas con el aire abierto/ de la Avenida 9 de Julio/ que se me cuelguen de ellas todos los que quieran/ Todos/ Que afuera no quede nadie/ Dos tetas democráticas/ Los colectiveros/ Los diarieros/ Los canillitas/ Los taxistas/ Los artistas/ Dos grandes tetas/ De madre puto estéril/ Amamantar al pueblo/ con gotas de erotismo lácteo/ Dos tetas/ Ser la vaca fálica porteña/ De hinchadas urbes/ que sostengan perversiones secretas/ Dos tetas que duelan/ al mundo que las vea/ con su gran corpiño de prejuicio/ tapándose los ojos/ sacudiéndose la mierda/ Pero imposible intento/ porque la mierda se pega/ y aunque la sacudas/ el olor queda/ y te recuerda su presencia/ Quiero si.../ Si, si/ yo quiero/ Dos grandes tetas/Que alberguen mi ilusión/ de mujer hecha y derecha/ Adolescentes lactantes/ naciendo al sexo/trepados de mis pezones/ como grandes toboganes/ Un Italpark de silicona/ 
Un samba de aceite industrial/ Y reír como loca de tetas al viento/ cantando sola/ Quiero eso...si...yo quiero eso.../ Dos grandes tetas/ Dos cosas quiero/ Quiero locura/ Quiero locura.../ locura y tetas (Menstrual, 2012, p. 197-202).

Este poema opera como paradigma desde el que la poeta retrató la corporalidad travesti en la que puedan confluir (o combinar) las tetas con un pene. Como dice el poema, esta imagen de sus dos tetas puede doler y molestar al mundo que las vea. Naty Menstrual encuentra en este gesto su locus estético. En este sentido, señaló que su literatura travesti trash "es como remover la mierda que la gente no quiere ver” (apud Moreno, 2013, s/p).

El trazo provocativo de Naty Menstrual se distanció de los horizontes narrativizados de los modelos femeninos anteriormente señalados. Ella tematizó su travestismo. En consecuencia, sus poemas prolongaron una ambigua corporalidad. En tal acto, su travestismo trash adquirió un valor estético y político.

Por lo expuesto su propuesta se puede enmarcar en un travestismo cuestionador. En su análisis de travestismo y teatro, Beatriz Trastoy y Perlas Zayas de Lima (2006) sistematizaron diferentes modalidades en las que se presentó el travestismo en el campo teatral de Buenos Aires $^{22}$. La modalidad escénica del travestismo cuestionador refiere a aquellos artistas que presentan de manera ambigua las marcas de género. Dicho travestismo desestabiliza el binarismo masculinofemenino al escenificar la artificialidad de los códigos sociales y culturales aprehendidos a partir de los que construimos nuestra identidad. Naty Menstrual no sólo puso en crisis las categorías de hombre o mujer, sino también las categorías que pueden definir las corporalidades que de estas se distancien.

\section{A Modo de Cierre: ¿̨uáles son los aportes de las deformances al devenir travesti?}

A lo largo de nuestro trabajo abordamos la identidad travesti de Naty Menstrual en la primera presentación de El Teje. En primera instancia, nos servimos de la perspectiva del teatro posdramático. En segunda instancia, de la perspectiva de los estudios de las performances. Y, en última instancia, nos servimos de un enfoque semiótico de los lenguajes escénicos; particularmente, del vestuario y maquillaje por un lado. Y, por otro lado, de la gestualidad, la voz y la palabra. La interrelación de tales lenguajes escénicos se caracterizó por una acen- 
tuada tensión genérica presente en la corporalidad de Naty Menstrual. Consideramos que nuestra construcción discursiva es producto de un doble movimiento. Por un lado, es un efecto de aquellos cuerpos que estuvieron ausentes en los discursos dominantes del pasado. Y, por otro lado, es un efecto de la presencia de las diversas corporalidades que emergen en los discursos dominantes contemporáneos.

Propio de su devenir travesti, la corporalidad de Naty Menstrual se alzó como una alternativa dentro de un campo de múltiples identidades. Dado que coincidimos con Lehmann en que "[...] toda interrogación sobre la estética teatral es ciega si, en la práctica artística del teatro, no reconoce la reflexión sobre las normas sociales de la percepción y del comportamiento" (2010, p. 5), consideramos que el travestismo de Naty Menstrual amplió el campo de pensamiento de lo posible al tiempo que mostró otros modos de estar en el mundo.

Nuestra labor consistió en describir y "[...] trazar los momentos en los que se disputa y se reta al sistema binario del género, en los que se cuestiona la coherencia de las categorías y en los que la vida social del género resulta ser maleable y transformable" (Butler, 2006, p. 305). Consideramos que las deformances poéticas de Naty Menstrual instituyeron dicho momento de la vida social de género. No obstante, debemos señalar que las convenciones teatrales operan como marcos tranquilizadores de la visibilización de las identidades abyectas. Por el contrario, las performances de género en contextos no teatrales son gobernadas por convenciones sociales punitivas y reguladoras (Butler, 2006a). Ejemplo de ello, fue la reivindicación de la diversidad de género de Naty Menstrual en el lanzamiento de $E l$ Teje. Y, su contrapunto, los discursos heteronormativos que intentan ausentar tal diversidad genérica como fue el caso de la divulgada entrevista televisiva que Chiche Gelblung le realizó a la performer en el año 2008.

Si bien reconocemos que el carácter político de las prácticas identitarias no debe reducirse a categorías estéticas (Fernández, 2004, p. 197), no soslayamos la potencia política que pueden tener la presencia de las propias travestis en las performances teatrales. En ellas, encontramos una de las instancias en las que las corporalidades resignifican, sedimentan y amplían el campo ontológico de la performatividad del género.

La presencia de Naty Menstrual se ubicó entre la liminalidad de lo real y lo ficcional. La poeta deformó las representaciones de 
género. En dicha liminalidad evidenció las fallas de las performances de género. Su presentación deconstruyó la identidad travesti. A la vez que mostró las limitaciones de las definiciones del campo teatral. Naty Menstrual, de manera irónica pero precisa, generó otros términos para nombrarse. En este trabajo, lejos de suponer las categorías como fijas y universales, nos aventuramos a promover otras y nuevas definiciones que amplíen el campo de lo posible. Por tal motivo, abordamos la performance de la poeta como deformance. A partir de ella, intentamos mostrar cómo Naty Menstrual desestabilizó convenciones sociales y teatrales en la primera presentación de El Teje. La primera revista de travestis en América Latina. 


\section{Notas}

${ }^{1}$ El presente trabajo se enmarca en el proyecto de investigación de mi tesis doctoral titulado Construcción de identidades trans en las propuestas teatrales del Centro Cultural Ricardo Rojas: Desde Batato Barea a El Teje. Este cuenta con la dirección de la Dra. Beatriz Trastoy y el aval de la Universidad de Buenos Aires bajo el otorgamiento de una beca doctoral UBACyT (2011-2014).

${ }^{2}$ En el año 2003 el gobierno de Néstor Kirchner instaló los Derechos Humanos en la agenda política. Esto implicó derogar los indultos militares decretados en la primera presidencia de Carlos S. Menem y re abrir los juicios por lesa humanidad cometidos en la última Dictadura Militar (1976- 1983). En la misma línea, Cristina Fernández de Kirchner profundizó la política de los Derechos Humanos. No obstante, su gobierno se caracterizó por ampliar e innovar en la agenda de los Derechos Humanos al incluir a la comunidad LGTBIQ. En consecuencia, el 10 de Julio del 2010 se promulgó la Ley de Matrimonio igualitario. Y el 9 de Mayo del 2012 se promulgó Ley de Identidad de género. Ambas leyes dieron cuenta de los avances de nuestro país en materia de Derechos.

${ }^{3}$ El neologismo indica la confluencia entre el activismo artístico y político.

${ }^{4}$ En el primer lanzamiento de El Teje (2007) se presentaron Julia Lagos, Dominique Sander, Julia Amore Naty Menstrual y Fernando Noy. El lanzamiento del tercer número (2009) fue acompañado por dos bandas musicales y performances poéticas de Susy Shock y Naty Menstrual. Y en el último lanzamiento (2012) Lukas Avendaño (México) presentó Requiem para un alcaraván.

${ }^{5}$ Conforme el Suplemento Soy de Pág./12 para conmemorar la aprobación de la Ley de Identidad de Género aunó en su publicación del 11 de Mayo del 2012 las voces más representativas del movimiento trans. Entre ellas Marlene Wayar y Naty Menstrual expusieron su radical punto de vista sobre la citada Ley. Disponible en: <http://www.pagina12.com.ar/ diario/suplementos/soy/1-2436-2012-05-11.html> y <http://www.pagina12.com.ar/diario/ suplementos/soy/1-2433-2012-05-11.html>. Acceso en: 02 mar. 2013.

${ }^{6}$ No existe registro audiovisual de la primera presentación de El Teje. Naty Menstrual no recuerda qué textos leyó. A partir de nuestro recuerdo y el de los asistentes y las crónicas de la presentación inferimos que uno de los poemas que leyó fue "Yo quiero tetas".

${ }^{7}$ Josefina Fernández (2007; 2004) señaló que las discusiones actuales del travestismos se centraron entre: la concepción del travestismo como un tercer género; como profundización de uno de los géneros existentes; o como un modo de develar el carácter ficcional del género.

${ }^{8}$ Una imagen travesti tradicional es aquella que borra los rasgos de masculinidad e imita los estereotipos de modelos femeninos (Fernández, 2004).

${ }^{9}$ Tarea esencial para la rearticulación de la competencia democrática (Butler, 2008).

${ }^{10}$ Según Taylor, "Performance' incluye pero no puede reducirse a los términos que usualmente se utilizan como sus sinónimos: teatralidad, espectáculo, acción o representación” (2005, p. 4). Por más información sobre los usos de la palabra performances ver: De Carvalho Biao (2011).

${ }^{11}$ En diálogo personal Naty Menstrual (2013) nos aclaró lo siguiente: "No hice performance en el Rojas. Presenté mi libro. No hago performance en el Rojas. No hago performance. Odio la palabra performances! Hice una puesta en escena. Hago un show de lectura expresiva. Me 
expreso mediante mi lectura. A lo sumo, sabes lo que hago? Hago deformances". Buenos Aires, mar. 2013.

${ }^{12}$ Josefina Fernández (2004) señaló que los cuerpos femeninos también están construidos sobre el lenguaje de la moda y la belleza. Agregó la antropóloga que las mujeres intervienen el cuerpo al igual que las travestis. Sin embargo, esta no es una situación equivalente ya que la transformación corporal de las travestis está orientada a superar el límite del cuerpo propio. Además dicha transformación tiende a ser realizada en solitario, sin el respaldo de las instituciones y la sociedad.

13 "Por lenguaje se entiende un sistema complejo y significativo, un código que, de acuerdo con una convención pre-establecida, intenta transmitir un mensaje del emisor al receptor. Las convenciones determinan la vinculación entre significado y significante sobre la base de un código [...]. El código ordena los elementos constitutivos al restringir sus posibilidades combinatorias y establecer entre sistemas de significantes equivalencias semánticas; éstas, aunque arbitrarias, deben ser aceptadas en una comunidad y en una época determinada. De este modo, son las convenciones las que instituyen los signos como instrumentos culturales" (Trastoy; Zayas de Lima, 2006, p. 14).

${ }^{14}$ Naty Menstrual, además de vender sus libros y hacer presentaciones para su subsistencia económica, vende remeras en la feria del barrio de San Telmo de la Ciudad Autónoma de Buenos Aires (C.A.B.A). El diseño de sus remeras se caracteriza por caricaturas paródicas y provocativas que se relacionan directamente con su literatura travesti trash. Disponible en: <http://natymenstrualremeras.blogspot.com.ar>. Acceso en: 02 mar. 2013.

${ }^{15}$ En la C.A.B.A existen una gran cantidad de ferias americanas (negocios de ropa usada). Podemos reconocer a jóvenes, artistas y disidentes al sistema de la moda como su clientela principal. Ellos encuentran en tales locales las prendas que individualizan su perfil. En dichas ferias las prendas llevan el precio escrito a mano y abrochado en el lugar bien visible. Tal cartel funciona como etiqueta. Naty Menstrual suele usar las prendas con este precio abrochado como gesto que acentúa su estilo de feria americana.

${ }^{16}$ En la jerga travesti refiere a aquellas travestis en situación de prostitución (o no) que intentan sacar un dinero extra de alguna relación personal.

${ }^{17}$ El nombre a la garçonne proviene de la novela homologa escrita por Victor Margueritte en el año 1922. Retrataba la liberación femenina de aquellos ańos motivo por el cual fue censurada. Con sus variantes, en Estados Unidos dicho estilo se conoció como flapper. El nombre provino de la película de Olive Thomas, The Flappers, de 1920. Básicamente el estilo a la garçonne consistía en: "Los cabellos se llevaban muy cortos y, con frecuencia, se los engominaban como los de los chicos. Los rizos o caracoles que adornaban la sien y que sobresalían bajo los sombreros eran las únicas concesiones hechas a la feminidad. No era fácil distinguir a una mujer de un colegial, de un chico o chica de 15 años. El corte de pelo llamado 'a la garçonne', junto con atuendos totalmente masculinos, les ayudaba a crear ese ideal erótico basado en lo andrógino. Junto con el corte de pelo, también se diseñaban sombreros acordes con la nueva imagen, el cloche [...] La nueva mujer de los años 20 olvida senos y caderas, la ropa era suelta y funcional. El largo de las faldas se va acortando poco a poco hasta llegar a la altura de la rodilla en 1925 [...] Otro aspecto novedoso era el uso que hacían del maquillaje: se pintaban los labios muy rojos, delgados y en forma de corazón, y se ponían brillantes sombras en los párpados, rimel en las pestañas, cejas delgadas y perfiladas. El maquillaje se tornó más abundante, con líneas más definidas, 
haciendo hincapié en una simplificación de las formas. Asimismo, dejó de estar de moda la piel blanca, siendo Chanel la gran impulsora del bronceado" (Iglesias, 2006, s/p).

${ }^{18}$ La historia del maquillaje se puede rastrear en pueblos originarios y en pueblos occidentales y orientales. Tanto en la Biblia como en el pueblo egipcio, romano y en los griegos la función del maquillaje fue estética. Asimismo en China y Japón también cumplía la misma función. Los investigadores destacan el grado de perfeccionamiento y refinamiento en su aplicación que alcanzaron estos dos últimos países (Carles Pastor et al, 1988).

${ }^{19}$ En diálogo personal con una amiga travesti me contó que ella misma preparaba su maquillaje. Y, dada la cantidad de maquillaje que utilizaba cotidianamente, cuando su economía se lo permitía, preparaba una gran cantidad para que nunca le falte.

${ }^{20}$ Naty Menstrual es egresada de la carrera de Locutor integral de radio y televisión del Instituto Superior de Enseñanza Radiofónica (ISER) de la C.A.B.A.

${ }^{21}$ La entrevista que Chiche Gelblung le realizó a Naty Menstrual en el programa televisivo Chiche en Vivo, transmitido en el Canal 26 en Noviembre de 2008, puso de manifiesto la transfobia mediática ante la ambigua imagen travesti de la performer. En la entrevista el conductor le dijo: "Vos de travesti lo único que tenés es la pilcha. Porque tenés vos de macho, tenes gestos de varón [...] Me sonas a travesti arrepentido". Esta entrevista se repitió en otros programas. En su mayoría con el mismo tono transfóbico. En esta línea, Guillermo López, conductor de Zapping $T V$, presentó el informe realizado llamando a Naty Menstrual como "el travesti Naty Mestrual" y no "la travesti Naty Menstrual". Tras nombrarla, un coro de voces (reidores contratados) exclamaron "Ehhhh". En primera instancia, el conductor pasó por alto la identidad femenina que instituye el nombre "Naty". En segunda instancia, el neologismo de la nominación operó como degradación a la identidad femenina que menstrua ("que mal gusto" respondió la co-conductora). Y, en tercera instancia, la respuesta de los reidores invalidó la posibilidad de un autopercibimiento femenino de las travestis. En este acto de transfobia de la televisión argentina, Guillermo López definió a Naty como "un travesti que le pone mucha voluntad a su imagen femenina pero la vocecita le da a pucho negro". Disponible en: <http://www.youtube.com/watch?v=JKbWspSezEY>. Acceso en: 7 mar. 2013.

${ }^{22}$ Las investigadoras establecieron siete modalidades en las que el travestismo se escenificó en el campo teatral de Buenos Aires. Estas son: 1) Travestismo estetizante; 2) Travestismo cuestionador; 3) Travestismo y la parodización de los roles sociales; 4) Travestismo y los género populares; 5) Travestismo tematizado; 6) Travestismo como opción de puesta en escena; 7) La mujer travestida.

\section{Referencias}

BARTHES, Roland. Ensayos Críticos. Barcelona: Seix Barral. 1967.

BUTLER, Judith. Cuerpos que importan. Sobre los límites materiales y discursivos del "sexo". Buenos Aires: Paidós, 2008 [2002].

BUTLER, Judith. El Género en Disputa. El Feminismo y la subversión de la identidad. Barcelona: Paidós, 2007 [1990].

BUTLER, Judith. Deshacer el Género. Barcelona: Paidós, 2006 [2004]. 
BUTLER, Judith. Actos Performativos y Constitución del Género. Un ensayo sobre fenomenología y teoría feminista. Traducción: Maurie Lourties. In: CASE, Sue-Ellen (Org.). Performing Femnisms: feminist critical theory and theatre. Baltimore: Johns Hopkins University Press, 2006 [1990]. P. 270-282.

CARLES PASTOR, María Rosa; JAVIERRE PÉREZ, Yolanda; SABARTÉS RUESCAS, María Mercedes. El maquillaje. In: FERNÁNDEZ ARENAS, José (Org.). Arte Efímero y Espacio Estético. España: Anthropos, 1988. P. 247-271.

CITRO, Silvia (Org.). Cuerpos Plurales. Antropología de y desde los cuerpos. Buenos Aires: Biblos, 2010.

CORNAGO BERNAL, Oscar. Resistir en la Era de los Medios. Estrategias preformativas en literatura, teatro, cine y televisión. Madrid: Iberoamericana Vervuert, 2005. P. 175-210.

DE CARVALHO BIAO, Armindo Jorge. A presença do corpo em Cena nos Estudos da Performance e na Etnocenologia. Revista Brasileira de Estudos da Presença, Porto Alegre, Universidade Federal do Rio Grande do Sul, v. 1, n. 2, p. 346-369, jul./dez. 2011.

DE LAURETIS, Teresa. La Tecnología del Género. Mona - Revista del Área Interdisciplinaria de Estudios de la Mujer, Buenos Aires, Universidad de Buenos Aires/Facultad de Filosofía y Letras, n. 2, p. 6-34, 1996 [1989].

DEMA, Verónica. Escribo para Tapar un Vacio. Diario La Nación, Buenos Aires, 12 sep. 2011. Disponible en: <http://blogs.lanacion.com.ar/boquitas-pintadas/arte-y-cultura/ naty-menstrual-escribo-para-tapar-un-vacio/>. Acceso: 03 mar. 2013.

FERNÁNDEZ, Josefina. Cuerpos Desobedientes. Travestismo e identidad de género. Buenos Aires: Edhasa, 2004.

FERNÁNDEZ, Josefina. Travestismo. In: GAMBA, Susana. Diccionario de Estudios de Género y Feminismo. Buenos Aires: Biblos, 2007. P. 330-332.

HINOJOSA I FAYES, Pilar. El Vestido y la Moda. In: FERNÁNDEZ ARENAS, José (Org.). Arte Efímero y Espacio Estético. España: Anthropos, 1988. P. 194-234.

ICLE, Gilberto. Estudios de la Presencia: del trabajo del actor a la investigación no interpretativa. Traducción: Elaine Padilha Guimarães. Telondefondo - Revista de Teoría y Crítica Teatral, Buenos Aires, Universidad Nacional de Buenos Aires/Facultad de Filosofía y Letras, n. 16, p. 189-204, dic. 2012. Disponible en: <http://www.telondefondo.org/>. Acceso en: 14 jun. 2013.

IGLESIAS, Charo. Sombrero Cloche. Modelos del Mes. Los modelos más representativos de la exposición, Museo del Traje, oct. 2006. Disponible en: <http://museodeltraje.mcu. es/popups/10-2006pieza.pdf/>. Acceso en: 07 mar. 2013.

LEHMANN, Hans-Thies. El Teatro Posdramático: una introducción. Traducción: Paula Rivas. Telondefondo - Revista de Teoría y Crítica Teatral, Buenos Aires, Universidad Nacional de Buenos Aires/Facultad de Filosofía y Letras, n. 12, p. 1-19, dic. 2010. Disponible en: <http://www.telondefondo.org/>. Acceso en: 14 dic. 2012.

MENSTRUAL, Naty. Nueva Ley de YPF: Ya Podemos Feminizarnos. Suplemento Soy, Buenos Aires, 11 may. 2012. Disponible en: <http://www.pagina12.com.ar/diario/suplementos/soy/1-2433-2012-05-11.html/>. Acceso en: 14 jun. 2013. 
MENSTRUAL, Naty. Batido de Trolo. Buenos Aires: Milena Cacerola, 2012.

MENSTRUAL, Naty. Continuadisimo. Buenos Aires: Eterna Cadencia, 2008.

MENSTRUAL, Naty. Entrevista a Naty Menstrual. Entrevista realizada por Guillermina Bevacqua. Buenos Aires, Bar MU, 15 mar. 2013. Sin publicar.

MORENO, María. Poética popo. Suplemento Soy, Buenos Aires, 01 feb. 2013. Disponible en: <http://www.pagina12.com.ar/diario/suplementos/soy/1-2798-2013-02-01.html/>. Acceso: 06 mar. 2013.

PALMEIRO, Cecilia. Desbunde y Felicidad. De la Cartonera a Perlongher. Buenos Aires: Título, 2010.

PAVIS, Patrice. Diccionario del Teatro. Dramaturgia, estética, semiología. Buenos Aires: Paidós, 2005.

PERALTA, Jorge Luis. Prólogo. Los géneros en dis/puta. In: MENSTRUAL, Naty. Batido de Trolo. Buenos Aires: Milena Cacerola, 2012. P. 7-10.

PERLONGHER, Néstor. Prosa Plebeya. Ensayos 1980-1992. Buenos Aires: Colihue. 1997.

SCHECHNER, Richard. Performance. Teoría y prácticas interculturales. Buenos Aires: Libros del Rojas, 2000.

TAYLOR, Diana. Hacia una Definición de 'Performances'. Revista El Picadero, Buenos Aires, Instituto Nacional del Teatro, a. V, n. 15, p. 3-5, sep./dic. 2005.

TRASTOY, Beatriz; ZAYAS DE LIMA, Perla. Lenguajes Escénicos. Buenos Aires: Prometeo, 2006.

TRASTOY, Beatriz; ZAYAS DE LIMA, Perla. Los Lenguajes no Verbales. Buenos Aires: Universidad de Buenos Aires/Oficina de Publicaciones del CBC, 1997.

WAYAR, Marlene. ¿Qué pasó con la T?. Suplemento Soy, Buenos Aires, 11 may. 2013. Disponible en: <http://www.pagina12.com.ar/diario/suplementos/soy/1-2436-2012-05-12. html/>. Acceso en: 03 feb. 2013.

WAYAR, Marlene. El Esplendor Revisteril en una Noche. El Teje. Primer periódico de travestis en América Latina, Centro Cultural Ricardo Rojas, Universidad de Buenos Aires, Buenos Aires, a. 2, n. 2, p. 2, may. 2008. Disponible en: <http://www.rojas.uba.ar/img/ libros/el-teje/teje_02.pdf/>. Acceso en: 22 nov. 2012.

WITTIG, Monique. El Pensamiento Heterosexual. Madrid: EGALES, 2006.

Guillermina Bevacqua es licenciada y profesora en Artes por la Facultad de Filosofía y Letras de la Universidad de Buenos Aires. Es becaria doctoral de la Universidad de Buenos Aires. Su investigación aborda la construcción de identidades trans en las propuestas teatrales del Centro Cultural Rector Ricardo Rojas de la Universidad de Buenos Aires. Dicha investigación cuenta con la dirección de la Dra. Beatriz Trastoy. E-mail: mina_bevacqua@hotmail.com 